\title{
Resistance against macrocyclic lactones in Psoroptes ovis in cattle
}

\author{
Wouter van Mol ${ }^{1 *}$, Nathalie De Wilde ${ }^{1}$, Stijn Casaert ${ }^{1}$, Zhenzhen Chen ${ }^{1}$, Marieke Vanhecke ${ }^{1}$, Luc Duchateau $^{2}$ \\ and Edwin Claerebout ${ }^{1}$
}

\begin{abstract}
Background: Psoroptic mange is an important disease in Belgian Blue cattle. Treatment failure of macrocyclic lactones against Psoroptes ovis has been reported, but clear evidence of in vivo resistance is lacking. This study assessed the efficacy of macrocyclic lactone products on 16 beef farms in Belgium and the Netherlands in vivo and in vitro.

Methods: On each farm a group of animals $(n=7-14)$ with psoroptic mange was treated with two subcutaneous injections of a macrocyclic lactone product with 7-10 days interval (15 farms) or a single injection with a long-acting macrocyclic lactone (1 farm). In vivo efficacy was assessed by the reduction in mite counts, clinical index (proportion of the body surface affected by lesions), the proportion of the animals with negative mite counts after the first treatment round and the number of treatment rounds needed to obtain zero mites counts in all animals. A mite population was categorized as sensitive when the mite count reduction after the first treatment round $>95 \%$ and the lower limit of the uncertainty interval $>90 \%$. Resistance was detected when both parameters were below their threshold and suspected when one parameter was too low. In vitro knockdown and mortality were evaluated in a contact test.

Results: The proportion of the animals with negative mite counts after the first treatment round varied from 0 to $80 \%$. All farms needed two or more treatments rounds to obtain zero mite counts on all animals. Clinical index only started to reduce after the second treatment round. Mite populations from three farms were categorized as sensitive, one as suspected resistant and 12 as resistant. No correlation was found between in vitro lethal dose 50 and knockdown dose 50 values and in vivo efficacy parameters.

Conclusions: Unambiguous treatment failure was detected on 12 out of 16 farms, confirming the presence of macrocyclic lactone resistance on Belgian Blue beef farms. In vitro parameters could not discriminate the farms based on their in vivo sensitivity. The mean reduction in mite counts and the lower limit of the confidence interval are proposed as parameters to identify acaricide resistance.
\end{abstract}

Keywords: Psoroptes ovis, Macrocyclic lactones, Resistance

\section{Background}

Psoroptic mange is a major skin problem in sheep and cattle. In cattle, psoroptic mange is predominantly seen in the Belgian Blue breed, due to their high susceptibility to Psoroptes ovis [1]. Psoroptes ovis infestation causes

\footnotetext{
*Correspondence: wouter.vanmol@ugent.be

${ }^{1}$ Laboratory of Parasitology, Faculty of Veterinary Medicine, Ghent University, Salisburylaan 133, 9820 Merelbeke, Belgium

Full list of author information is available at the end of the article
}

an exudative perivascular dermatitis with intense pruritus and formation of crusts. The predilection site is from the withers to the tail base. Excessive scratching causes lesions which have a higher chance of secondary bacterial infection. In extreme cases, the lesions can generalize and result in the death of the animal [1-4]. Diminished animal welfare and financial losses are seen on farms with P. ovis problems $[5,6]$.

Registered treatments in Europe are limited to topical acaricides, such as amitraz or synthetic pyrethroids, and 
parenteral administration of macrocyclic lactones (ML). Topical application of ML products is not recommended, due to contradictory publications about their efficiency to completely eliminate $P$. ovis [7]. In practice, it is recommended to apply acaricides twice with a 7-10-day interval, probably due to a lack of full ovicidal efficacy [7, 8]. Long-acting (LA) ML products only need one application, because of their long persistent activity [8-12]. Additional measures are crucial to get the desired treatment result. The hair needs to be sheared and crusts need to be removed prior to treatment. Treatment should be applied to all in-contact animals and not only the clinically infested animals $[3,7,11,12]$.

Treatment failure with ML products in cattle has been reported by Lekimme et al. [13], Mitchell et al. [14] and Sarre et al. [3]. Potential reasons for treatment failure are noncompliance with the recommended 'good practice' treatment and acaricide resistance. Suboptimal treatment cannot be ruled out in the studies mentioned above, as either a long treatment interval (14 days) was used [13] or not all animals were treated in every treatment round [3]. Sarre et al. [15] mentioned that less than half of the Belgian farmers applied correct treatment against Psoroptes. Commonly made mistakes include underdosing, a single treatment, a long treatment interval, the use of a suboptimal drug formulation or a lack of additional control measures, e.g. failing to shear the animals or partial treatment of the herd [15]. Recently, decreased in vitro sensitivity to ML products was seen in mites collected from sheep farms with reported treatment failure [16, 17]. Lifschitz et al. [18] reported treatment failure in cattle, despite repeated subcutaneous injection of two commercial formulations of ivermectin (1\%) at $0.2 \mathrm{mg} / \mathrm{kg}$ with a short treatment interval (1 week).

Despite numerous field observations and a few published reports of treatment failure against $P$. ovis in cattle, the presence of resistant mites was not confirmed $[3,13,18]$. The objectives of this study were (i) to investigate the presence of ML resistance in beef cattle in Belgium and The Netherlands using different in vivo parameters; and (ii) to evaluate an in vitro test based on the method of Brimer et al. [19] as a potential diagnostic tool for ML resistance in P. ovis.

\section{Methods}

\section{Animal selection}

Sixteen Belgian Blue beef farms with psoroptic mange were visited during the housing period during the winters of 2016-2017, 2017-2018 and 2018-2019. Skin scrapings were collected from two to five animals per farm to confirm active $P$. ovis infestations.

A group of 7 to 13 animals was selected on each farm. Male or female cattle older than 4 months were used. The experimental group was separated from the rest of the herd and animals in adjacent pens were treated with an acaricide (injectable ML product or topical treatment with amitraz, twice with one-week interval) for the duration of the study, to preclude re-infestation of the study animals.

\section{Animal treatment}

All animals were treated with a commercially available injectable ML product, i.e. ivermectin (Ivomec ${ }^{\circledR}$, Merial, Toulouse, France), doramectin (Dectomax ${ }^{\circledR}$, Zoetis Belgium SA, Louvain-la-Neuve, Belgium) or moxidectin (Cydectin $^{\circledR}$, Zoetis, Girona, Spain) at the recommended dose rate. On one farm, a long-acting formulation of moxidectin (Cydectin $10 \% \mathrm{LA}^{\circledR}$, Zoetis) was used. The animals were weighed on a calibrated weighing scale to determine the dose prior to treatment. In absence of a weighing scale, heart girth measurements were used to estimate the body weight [20]. All animals were sheared prior to the first treatment administration and crusts were removed as much as possible during shearing. Fresh bedding with or without cleaning of the stable was applied at least once per week.

A treatment round consisted of two injections with a 7-10-day interval or a single injection with a long-acting ML product, as recommended by the manufacturer. Treatment was evaluated 7 days after the second administration or 14 days after administration of a long-acting ML product. If living $P$. ovis were found in one or more animals at a given farm, a new treatment round was started for all the animals in the experiment.

Treatment with ML products was terminated when all animals had negative $P$. ovis mite counts, when the cattle were turned out on pasture at the end of the housing period or if the condition of the animals warranted salvage treatment. In the latter case, animals were treated topically with amitraz (Taktic $^{\circledR}$, MSD Animal Health, Brussel, Belgium) two times with a one-week interval at the recommended dose.

\section{In vivo efficacy}

The clinical index $(\mathrm{CI})$ and mite counts $(\mathrm{MC})$ were determined before the first treatment and after every treatment round. The CI is the proportion of the total body surface with clinical lesions. A CI was assigned to all animals by recording the skin lesions (on both sides of the animal) on a silhouette [21].

Skin scrapings from three different locations at the edge of the lesions $\left(9 \mathrm{~cm}^{2} /\right.$ sampling location) were collected in one tube per animal for MC. If sampling threatened to influence the treatment results (in case of very small lesions), samples were taken from the predilection sites (withers, back, tail basis). Samples were stored at $10^{\circ} \mathrm{C}$ and analysed within $24 \mathrm{~h}$ after collection to identify and count living $P$. ovis mites using a stereoscopic microscope (magnification $100 \times$ ). If the mites were too numerous to count, the sample was weighed, $1 \mathrm{~g}$ was taken and 
mites were counted as previously described. Mite numbers were then recalculated to the total mite count of the pooled sample.

\section{In vitro sensitivity}

An in vitro test was based on Brimer et al. [19]. Sterile polystyrene Petri dishes with an internal diameter of 92

$$
\operatorname{RedMC}(\%)=100\left(1-\frac{\overline{\mathrm{MCA}}}{\overline{\mathrm{MCB}}}\right)
$$

where $\overline{\mathrm{MCB}}$ and $\overline{\mathrm{MCA}}$ is the mean $\mathrm{MC}$ value of a number of cows before and after the first treatment round, respectively, with its variance approximated by the delta method as

$$
\operatorname{Var}(\operatorname{RedMC})=\left(\frac{\overline{\mathrm{MCA}}}{\overline{\mathrm{MCB}}}\right)^{2}\left(\frac{\operatorname{Var}(\overline{\mathrm{MCA}})}{\overline{\mathrm{MCA}}}+\frac{\operatorname{Var}(\overline{\mathrm{MCB}})}{\overline{\mathrm{MCB}}}-2 \frac{\operatorname{Corr}(\overline{\mathrm{MCA}}, \overline{\mathrm{MCB}}) \sqrt{\operatorname{Var}(\overline{\mathrm{MCA}}) \operatorname{Var}(\overline{\mathrm{MCB}})}}{\overline{\mathrm{MCA}} \overline{\mathrm{MCB}}}\right)
$$

mm were filled with $20 \mathrm{ml}$ sterile agar solution (Bidest with $42 \mathrm{~g} /$ litre Columbia agar, Sigma-Aldrich, St. Louis, USA) containing $1 \mathrm{ml}$ horse serum (food source) and 0 , $1,10,100,1000,2000$ and $5000 \mu \mathrm{g} / \mathrm{ml}$ ivermectin $(1 \%$ Ivomec $^{\circledR}$, Boehringer-Ingelheim).

The in vitro sensitivity was determined on mites from pooled skin scrapings from each farm. Ten mites (adults and nymphs from Farms 1-10, adult mites form Farms 11-16) from each pooled sample were transferred to the centre of the Petri dish. The plates were kept at room temperature for $24 \mathrm{~h}$. The mites were inspected under a stereomicroscope at $0,2,4,6,8$ and $24 \mathrm{~h}$ of incubation. Immobility of mites and a lack of reactions or persistent immobility within $1 \mathrm{~min}$ following stimulation with a needle were considered indications of death. All concentrations were tested in triplicate, except for Farms 1 and 8. The test for Farm 1 was conducted in duplo and without the $5000 \mu \mathrm{g} / \mathrm{ml}$ ivermectin plates. This concentration was added afterwards for the other farms, as 50\% mortality was not achieved with lower concentrations on Farm 1. Farm 8 was tested in duplo, due to a shortage of mites.

Additional time points and an extra parameter ('knockdown') were monitored for Farms 11-16. The status of the mites was recorded at $0,5 \mathrm{~min}, 0.5,1,2,4,6,8,24$, 48, 72 and $120 \mathrm{~h}$ of incubation. Knockdown was defined as the absence of spontaneous mobility, while movement was still observed after stimulation with a needle.

\section{Statistical analysis}

\section{In vivo efficacy}

Multiple parameters were monitored in vivo, i.e. number of treatment rounds until all animals at a given farm had a mite count of zero (nTR), reduction in MC after first treatment round (RedMC), CI reduction after two treatment rounds (RedCI) and the proportion of the animals with zero mite counts after the first treatment round.

RedMC is defined as
Assuming that $100-\operatorname{Red}_{\mathrm{MC}}$ follows a gamma distribution with shape parameter $\gamma$ and scale parameter $\theta$ given by

$$
\gamma=\frac{(1-\operatorname{RedMC})^{2} n}{\operatorname{Var}(\operatorname{Red} M C)}, \theta=\frac{\operatorname{Var}(\operatorname{Red} M C)}{(1-\operatorname{RedMC})^{2} n}
$$

the lower limit (LL) and upper limit (UL) of the 95\% confidence interval correspond to the 2.5th and the 97.5th quantile of the gamma distribution with shape parameter $\gamma$ and scale parameter $\theta$.

The RedMC and its LL and UL where then calculated for each farm. Calculations were done with the Paradrug tool $^{\circledR}$ (www.starworms.org/tools). Mite isolates of a farm were then categorized according to the methodology used for the faecal egg count reduction test in gastrointestinal nematodes, with the highest sensitivity [22]. The mite population on a farm was considered sensitive when RedMC $\geq 95 \%$ and $L L \geq 90 \%$, suspected of resistance when RedMC $<95 \%$ or $\mathrm{LL}<90 \%$ and resistant when RedMC $<95 \%$ and $\mathrm{LL}<90 \%$.

The proportion of the animals with negative mite counts was the fraction that was successfully treated $(\mathrm{MC}=0)$ after the first treatment round.

\section{In vitro sensitivity}

The lethal dose $50\left(\mathrm{LD}_{50}\right)$ values for each farm population was calculated for the survival at $24 \mathrm{~h}$ and $120 \mathrm{~h}$ and knockdown dose $50\left(\mathrm{KD}_{50}\right)$ values at $24 \mathrm{~h}$ using a mixed logistic regression model with mortality and knockdown as binary response variable, drug concentration as continuous independent variable and farm as random effect.

Spearman's rank correlations were calculated between nTR, RedMC, RedCI, mite free proportion and $\log \left(\mathrm{LD}_{50}\right)$. Regression analysis was done by fitting a linear model with nTR, mean $\operatorname{Red}_{\mathrm{MC}}$, mean $\operatorname{Red}_{\mathrm{CI}}$ or the proportion of the animals with negative mite counts as independent variable and $\log \left(\mathrm{LD}_{50}\right)$ as dependent variable. All calculations were done in $\mathrm{R}$ (version 3.5.1.) [23]. 


\section{Results}

\section{Participating farms}

The farms were located in Flanders, northern Belgium, $(n=13)$ and the Zeeland province of The Netherlands, bordering Belgium $(n=3)$. Group sizes varied from 7 to 13 animals/farm. The injectable ML products used were ivermectin (Ivomec ${ }^{\circledR} 1 \%, n=5$ ), doramectin (Dectomax ${ }^{\circledR}$, $n=11$ ), moxidectin (Cydectin ${ }^{\circledR} 1 \%, n=1$ ) and moxidectin long-acting (Cydectin 10\% LA ${ }^{\circledR}, n=1$ ). One farmer switched from ivermectin to doramectin after the third injection. Moxidectin long-acting was only used on one farm during the first treatment round. Afterwards, the farmer used doramectin.

\section{In vivo efficacy}

All farms needed at least two treatment rounds and one farm even up to 6 rounds, to count zero mites in all animals at a given farm. The proportion of the animals with negative mite counts after the first treatment round varied between $0-80 \%$. The individual mite counts per animal are shown in Fig. 1.

RedMC varied from $-82.5 \%$ to $99.3 \%$ (Table 1 ). The RedMC and the corresponding uncertainty interval of the mite populations on all the given farms are illustrated in Fig. 2. Treatment with ML products was terminated on four farms before all animals of those farms had a mite count of zero, due to unsatisfying treatment results (Farms 2, 4 and 5) or the end of the housing period approached (Farm 1). These groups were successfully treated with amitraz (results not shown).

The evolution of the $\mathrm{CI}$ of the animals on the different farms is depicted in Fig. 3. The mean CI before treatment varied between $1-14 \%$. On most farms, the skin lesions were completely healed $(\mathrm{CI}=0)$ at the end of the treatments. Farms 1, 4 and 10 had a mean CI of $1 \%$ at the end of the treatment. Only Farm 5 did not show any overall improvement of the CI during treatment.

\section{In vitro sensitivity}

The $\mathrm{LD}_{50}$ values at $24 \mathrm{~h}$ in mite populations from Farm 1 to 16 varied from $2951 \mu \mathrm{g} / \mathrm{ml}$ to $94,499 \mu \mathrm{g} / \mathrm{ml}$ with some populations not even reaching $50 \%$ mortality. The additional time point of $120 \mathrm{~h}$ for Farm 11 to 16 provided $\mathrm{LD}_{50}$ values from $0.3 \mu \mathrm{g} / \mathrm{ml}$ to $58.3 \mu \mathrm{g} / \mathrm{ml}$ (Table 2).

$\mathrm{KD}_{50}$ were determined for Farm 11 to 16 and varied from 0.05 to $0.77 \mu \mathrm{g} / \mathrm{ml}$ ivermectin at $24 \mathrm{~h}$. Neither LD nor KD allowed for a clear discrimination of the mite populations of the cattle of the 16 farms.

The regression analysis showed no correlation between in vivo parameters and in vitro $\mathrm{LD}_{50}$ values. Spearman's rank correlations were low $(-0.28-0.36)$ and $P$-values were too high (0.338-0.730).

\section{Discussion}

When ML products were introduced in the market, injectable ML products were highly effective against $P$. ovis. A single administration of the recommended (commercialised) dose of an injectable ML product was sufficient to kill the mites and obtain clinical cure [24-28]. In practice, a second injection is recommended to get the desired efficacy [7, 25].

In the present study, two or more treatments with weekly intervals were insufficient to eliminate $P$. ovis. Treatment failure of ML products against $P$. ovis has been reported in sheep and cattle [3, 13, 16, 18]. Although treatment failure can often be attributed to non-compliance with recommended treatment and control measures [15], resistance of $P$. ovis populations against ML is suspected as a cause of treatment failure [16-18] and could be the result of decades of frequent and indiscriminate use of ML.

In this study, confounding factors that could interfere with the detection of ML resistance were eliminated as much as possible. On all farms, the experimental animals were treated according to 'good practice', including weighing/girth measurements to determine the dose rate, use of an injectable formulation and treatment of the whole group with appropriate treatment interval. Prior to treatment, crusts were removed manually and the animals were sheared, to optimise treatment efficacy. Despite these efforts, poor (or no) mite count reductions were obtained after the first treatment round and multiple treatment rounds were needed to eliminate the mites and to obtain healing of the skin.

Although ML concentrations in the skin were not determined, it seems unlikely that treatment failure was due to low ML concentration in the skin of the treated animals, given the high number of treatments with short time intervals. Lifschitz et al. [18] showed high skin levels of ivermectin in cattle after two injections with a sevenday interval. Although BB cattle are more susceptible to psoroptic mange than other breeds, ML concentrations in the plasma and skin of BB were actually higher than in Holstein-Friesian animals [29]. Based on the above, the observed treatment failure in the present study is highly indicative for ML resistance.

The reduction in $\mathrm{MC}$ after the first treatment round appeared to be the best parameter to discriminate between sensitive and resistant mite populations, as $\mathrm{MC}$ reductions directly measure the effect of the ML on the population of mites. The number of treatment rounds and the proportion of the animals with negative mite counts after the first treatment round did not discriminate between populations, although they are derived from the reduction in MC. CI failed to differentiate between populations after treatment, since clinical 

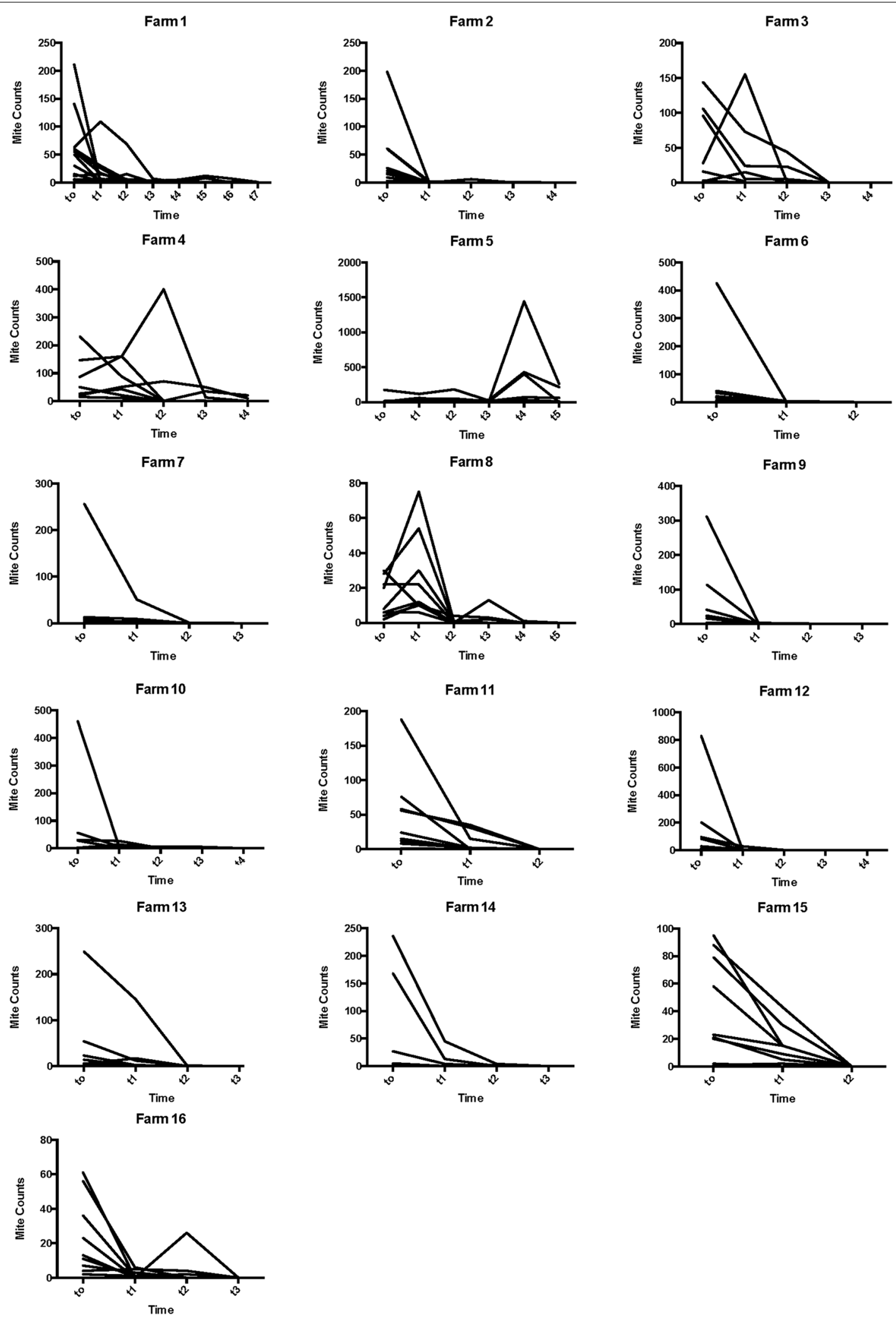

Fig. 1 The individual mite counts of each animal (sum of the three pooled samples) are depicted for the 16 farms. MC are given on the $y$-axis and time in number of treatment rounds on the $x$-axis. to refers to the count prior to the initiation of the first treatment round, $t 1$ is after the first treatment round, etc. Each line depicts MC values of one animal over time 
Table 1 In vivo efficacy of macrocyclic lactone products against Psoroptes ovis on 16 Belgian Blue beef farms in Belgium and the Netherlands

\begin{tabular}{|c|c|c|c|c|c|c|c|}
\hline Farm & No. of animals & Acaricide & RedMC (\%) & $95 \% \mathrm{Cl}$ & Resistance status & nTR & $\begin{array}{l}\text { Mite-free } \\
\text { proportion } \\
\text { (\%) }\end{array}$ \\
\hline 1 & 13 & IVM & 68.5 & $25.4-93.2$ & Resistant & $>7$ & 0/13 (0) \\
\hline 2 & 10 & IVM & 99.3 & $97.7-100$ & Sensitive & 4 & 8/10 (80) \\
\hline 3 & 9 & IVM /DOR & 33.3 & -65.8 to 87.6 & Resistant & 3 & $2 / 9(22)$ \\
\hline 4 & 7 & MOX-LA DOR & 7.6 & -58.6 to 56.1 & Resistant & $>4$ & $0 / 7(0)$ \\
\hline 5 & 9 & IVM & -36.8 & -200.7 to 63.0 & Resistant & $>5$ & 0/7 (0) \\
\hline 6 & 9 & DOR & 97.8 & $92.4-99.0$ & Sensitive & 2 & 4/9 (44) \\
\hline 7 & 9 & DOR & 78.5 & $72.2-83.9$ & Resistant & 4 & $2 / 9(22)$ \\
\hline 8 & 9 & IVM & -82.5 & -203.1 to 7.8 & Resistant & 5 & $2 / 9(22)$ \\
\hline 9 & 10 & DOR & 97.8 & $94.0-99.7$ & Sensitive & 3 & $5 / 10(50)$ \\
\hline 10 & 9 & MOX & 89.7 & $65.4-99.5$ & Resistant & 4 & $2 / 9(22)$ \\
\hline 11 & 9 & DOR & 80.4 & $56.7-94.8$ & Resistant & 2 & $3 / 9(33)$ \\
\hline 12 & 9 & DOR & 95.8 & 86.2-99.8 & Suspected resistant & 4 & $1 / 9(11)$ \\
\hline 13 & 8 & DOR & 50.3 & $29.7-67.8$ & Resistant & 3 & $4 / 8(50)$ \\
\hline 14 & 8 & DOR & 86.2 & $77.8-92.7$ & Resistant & 3 & $5 / 8(63)$ \\
\hline 15 & 10 & DOR & 65.5 & $51.6-77.0$ & Resistant & 2 & $2 / 10(20)$ \\
\hline 16 & 9 & DOR & 92.0 & $82.6-97.8$ & Resistant & 3 & $3 / 9(33)$ \\
\hline
\end{tabular}

Abbreviations: Cl, confidence interval; IVM, ivermectin injectable (Ivomec 1\% $\left.{ }^{\circledR}\right)$; DOR, doramectin injectable (Dectomax $\left.{ }^{\circledR}\right)$; MOX, moxidectin injectable $\left(\right.$ Cydectin $\left.{ }^{\circledR}\right)$; LA, moxidectin injectable long-acting formulation; RedMC, average reduction in mite counts on a given farm after the first treatment round; nTR, number of treatment rounds until all animals at a given farm had a mite count of zero; mite-free proportion, the proportion of the animals with negative mite counts after the first treatment round

recovery requires more time than mite eradication. This is also observed in ML sensitive mites [12].

To date, no threshold for mite count reductions has been defined to distinguish sensitive from resistant mite populations in vivo. We have based our classification of resistance on the methodology with highest sensitivity to detect anthelmintic resistance in ruminant nematodes using a faecal egg count reduction test [22, 30]. Using the LL of the UI and the RedMC described by Coles et al. [30], we identified three farms with sensitive mites, one farm was classified as 'suspected resistance' and 12 farms had resistant mite populations. This methodology was used because of the lack of resistance guidelines for ectoparasites in cattle. The World Association for the Advancement of Veterinary Parasitology (WAAVP) and the European Medicines Agency do have guidelines for the efficacy of new acaricides, recommending $\mathrm{MC}$ as efficacy parameter and a $90 \%$ mean reduction in $\mathrm{MC}$ after treatment as sufficient [31, 32]. Compared with these guidelines for acaricide efficacy, the thresholds we used to distinguish sensitive from resistant mite isolates may seem to be harsh. However, survival of $10 \%$ of the mites could quickly result in a relapse of psoroptic mange in the treated animals, as the mite population can double in size every six days under favourable conditions [33]. Moreover, even if the WAAVP efficacy guidelines for acaricide efficacy would have been followed, ML efficacy would only be sufficient on 5 out of 16 farms (MC reduction $>90 \%$ ), which supports our conclusion that ML resistance is widespread in $\mathrm{BB}$ farms in northern Belgium and the south of the Netherlands. The presence of ML resistance in Belgium is no surprise, since compliance with the recommended treatment is poor in the majority of Belgian beef farmers [15]. The emergence of ML resistance in P. ovis in beef farms in different countries (Argentina, Belgium, the Netherlands) is concerning and needs further investigation. Beef farmers should be instructed about good practices in mange control to slow down further spreading and development of resistance. Research is ongoing to identify the factors that may impede or facilitate adoption of these practices among farmers [34].

An in vitro test based on exposure of mites to different concentrations of acaricides on agar plates [19] has been used to differentiate sensitive and resistant mites [16]. An 


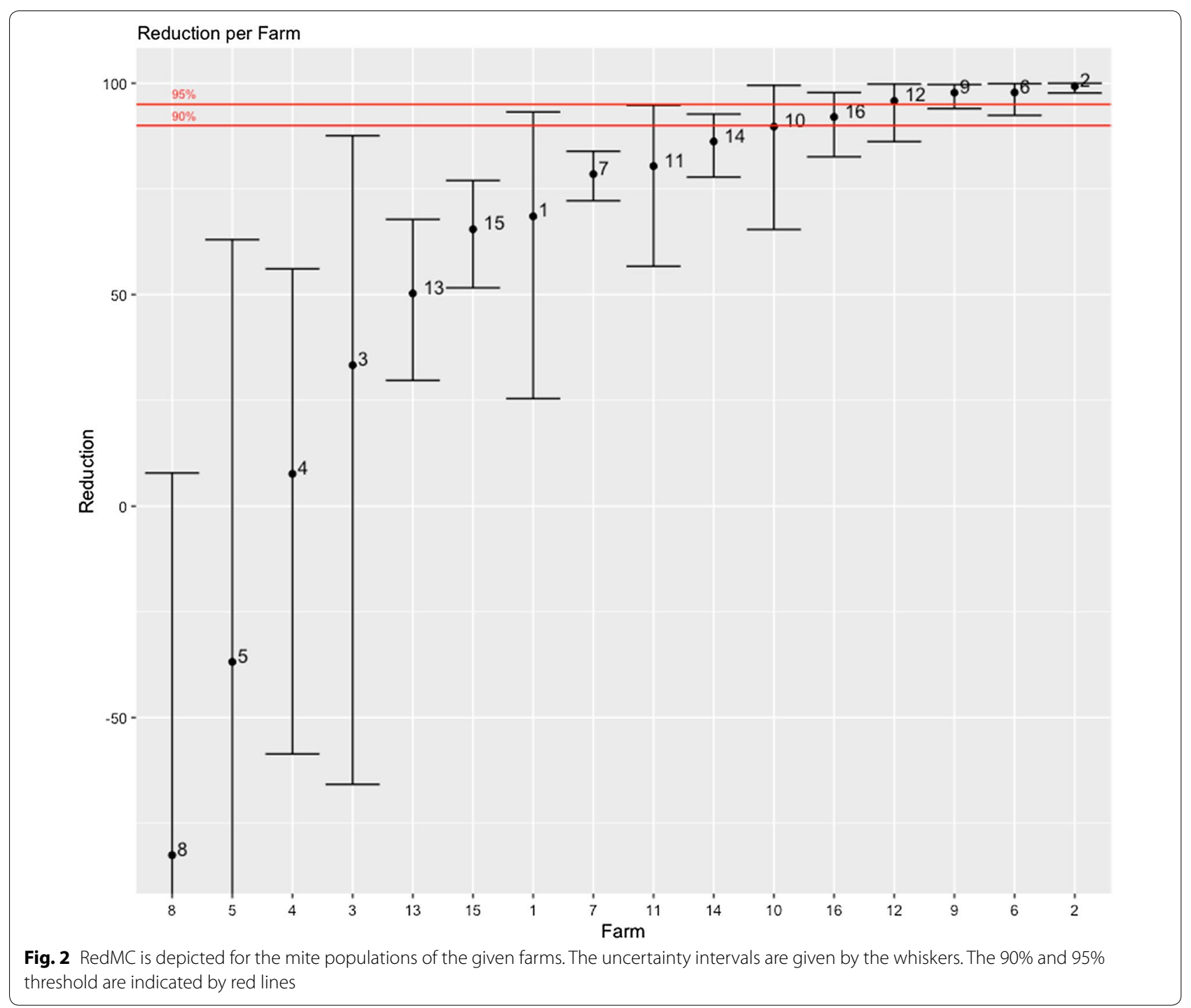

in vitro test would be useful to determine the resistance status of mite populations without the need to perform a labour-intensive mite count reduction test. However, in our hands, the in vitro test failed to distinguish the mite populations with different in vivo sensitivity from each other and in vitro test results did not correlate with in vivo efficacy. Despite large differences in MC reductions and $\mathrm{CI}$ reductions between farms, the in vitro efficacy showed a similar pattern in all farms and $L_{50}$ values or $\mathrm{KD}_{50}$ values did not vary with in vivo efficacy. The reason for this is unknown. To our knowledge, data about the reproducibility between laboratories are not available $[19,22]$.

\section{Conclusions}

Unambiguous treatment failure of ML products was detected on 12 out of 16 beef farms, confirming the presence of ML resistance in Belgian Blue beef farms in Belgium and the Netherlands. Tentative in vitro parameters could not detect ML resistance. The reduction in mite counts after the first treatment round (two administrations of an injectable ML product) appears to be a suitable parameter to monitor acaricide resistance. A mean reduction in mite counts of $<95 \%$ combined with a lower limit of the $95 \%$ uncertainty interval $<90 \%$ are proposed as criteria for the detection of resistance against ML in P. ovis. 


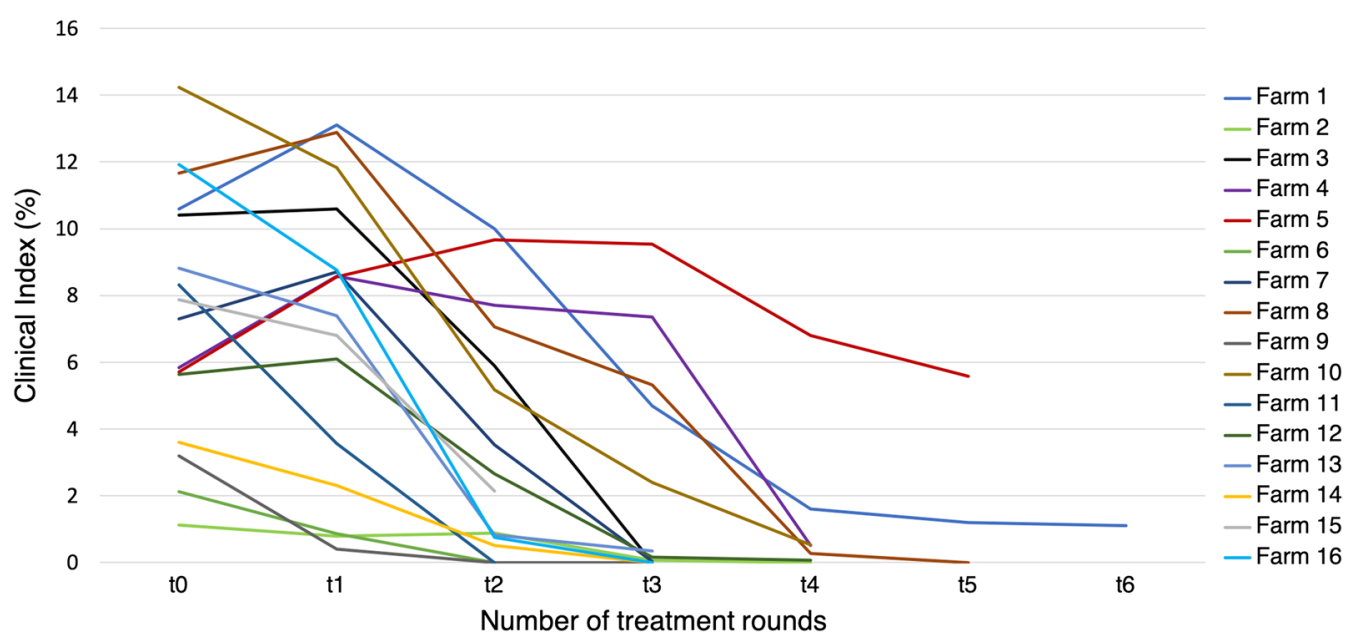

Fig. 3 The progress of the clinical index for the animals on each farm. to refers to the clinical index prior to the first treatment round, $t 1$ is the clinical index after the first treatment round, $\mathrm{t} 2$ is the clinical index after the second treatment round ... t6 is the clinical index after the sixth treatment round

Table $2 \mathrm{LD}_{50}$ at $24 \mathrm{~h}$ and at $120 \mathrm{~h}$ and $\mathrm{KD}_{50}$ at $24 \mathrm{~h}$ for ivermectin in P. ovis populations from 16 Belgian Blue farms in Belgium and the Netherlands

\begin{tabular}{llll}
\hline Farm & $\mathrm{LD}_{50} ; 24 \mathrm{~h}(\mu \mathrm{l} / \mathrm{ml})$ & $\mathrm{LD}_{50} ; 120 \mathrm{~h}(\mu \mathrm{l} / \mathrm{ml})$ & $\mathrm{KD}_{50} ; 24 \mathrm{~h}(\mu \mathrm{l} / \mathrm{ml})$ \\
\hline 1 & 36867 & na & na \\
2 & 2951 & na & na \\
3 & 2992 & na & na \\
4 & 3972 & na & na \\
5 & 3417 & na & na \\
6 & 3430 & na & na \\
7 & 4172 & na & na \\
8 & 3121 & na & na \\
9 & 3175 & na & na \\
10 & 3304 & na & na \\
11 & $6.538 \times 10^{6}$ & 23.1 & 0.19 \\
12 & 11.337 & 2.7 & 0.08 \\
13 & 3191 & 0.3 & 0.18 \\
14 & 7429 & 58.3 & 0.05 \\
15 & 6857 & 10.4 & 0.33 \\
16 & 94499 & 3.6 & 0.77 \\
\hline
\end{tabular}

Abbreviation: na, data not available

\section{Abbreviations}

ML: macrocyclic lactones; LA: long-acting; Cl: clinical index; MC: mite counts; nTR: number of treatment rounds; RedMC: reduction in mite counts; RedCl: reduction in clinical index; $\overline{\mathrm{MCB}}$ : mite counts before the first treatment round; $\overline{M C A}$ : mite counts after the first treatment round; $L L$ : lower limit of the confidence interval; $\mathrm{LD}_{50}$ : lethal dose $50 ; \mathrm{KD}_{50}$ : knockdown dose 50; IVM: ivermectin; DOR: doramectin; MOX: moxidectin.

\section{Acknowledgments}

We would like to thank all the farmers and veterinarians for their participation.

\section{Authors' contributions}

WVM participated in the design of the study, manuscript writing, data analysis and performed the experiments. NDW, SC and MV participated in the in vivo efficacy studies. ZC assisted with the in vitro assays. LD performed the statistical analysis and contributed to the writing of the manuscript. EC designed the study and participated in the manuscript writing. All authors read and approved the final manuscript.

\section{Funding}

This study was funded by a Special Research Fund-Interdisciplinary Research Project (BOF-IOP) from Ghent University (Grant code BOF.24J.2016.0004.01).

\section{Availability of data and materials}

Data supporting the conclusions of this article are included within the article. The datasets used and/or analysed during the present study are available from the corresponding author upon reasonable request.

\section{Ethics approval and consent to participate}

Ethical approval to conduct this study was obtained from the Ethical Committee of the Faculties of Veterinary Medicine and Bio-engineering Sciences, Ghent University (Ethical approval number EC2016/42). All participating farmers gave consent to conduct the study on their animals.

\section{Consent for publication}

Not applicable.

Competing interests

The authors declare that they have no competing interests.

\section{Author details}

${ }^{1}$ Laboratory of Parasitology, Faculty of Veterinary Medicine, Ghent University, Salisburylaan 133, 9820 Merelbeke, Belgium. ${ }^{2}$ Biometrics Research Center, Faculty of Veterinary Medicine, Ghent University, Salisburylaan 133, 9820 Merelbeke, Belgium.

Received: 11 December 2019 Accepted: 6 March 2020

Published online: 14 March 2020 


\section{References}

1. Losson BJ, Lonneux JF, Lekimme M. The pathology of Psoroptes ovis infestation in cattle with a special emphasis on breed difference. Vet Parasitol. 1999;83:219-29.

2. Pruett JH, Guillot FS, Fisher WF. Humoral and cellular immunoresponsiveness of stanchioned cattle infested with Psoroptes ovis. Vet Parasitol. 1986;22:121-33.

3. Sarre C, Geurden T, Vercruysse J, De Wilde N, Casaert S, Claerebout E. Evaluatie van twee intensieve behandelingsschema's tegen Psoroptes ovis-schurft bij Belgisch witblauwe runderen op negen Vlaamse rundveebedrijven. Vlaams Diergeneeskd Tijdschr. 2015;84:311-7.

4. van den Broek AH, Huntley JFÃ. Sheep scab: the disease, pathogenesis and control. J Comp Pathol. 2003;128:79-91.

5. Rehbein S, Visser M, Meyer M, Lindner T. Ivermectin treatment of bovine psoroptic mange: effects on serum chemistry, hematology, organ weights, and leather quality. Parasitol Res. 2016:115:1519-28.

6. Lonneux JF, Nguyen TQ, Detry J, Farnir F, Losson BJ. The relationship between parasite counts, lesions, antibody titres and daily weight gains in Psoroptes ovis infested cattle. Vet Parasitol. 1998;76:137-48.

7. Vercruysse J, Rew RS. The use of macrocyclic lactones to control parasites of cattle. In: Vercruysse J, Rew RS, editors. Macrocyclic lactones in antiparasitic therapy. Wallingford: CABI Publishing; 2002.

8. Lekimme M, Mignon B, Leclipteux T, Tombeux S, Marechal F, Losson B. In vitro tests for evaluation of the hatchability of the eggs of Psoroptes mites following exposure to acaricidal compounds. Med Vet Entomol. 2006;20:102-5.

9. Bridi AA, Carvalho LA, Cramer LG, Barrick RA. Efficacy of a long-acting formulation of ivermectin against Psoroptes ovis (Hering, 1838) on cattle. Vet Parasitol. 2001;97:277-83.

10. Lifschitz A, Virkel G, Ballent M, Sallovitz J, Imperiale F, Pis A, et al. Ivermec tin (3.15\%) long-acting formulations in cattle: absorption pattern and pharmacokinetic considerations. Vet Parasitol. 2007;147:303-10.

11. O'Brien DJ. Treatment of psoroptic mange with reference to epidemiology and history. Vet Parasitol. 1999;83:177-85.

12. Lonneux JF, Nguyen TQ, Losson BJ. Efficacy of pour-on and injectable formulations of moxidectin and ivermectin in cattle naturally infected with Psoroptes ovis: parasitological, clinical and serological data. Vet Parasitol. 1997:69:319-30.

13. Lekimme $M$, Farnir F, Maréchal F, Losson B. Failure of injectable ivermectin to control psoroptic mange in cattle. Vet Rec. 2010;167:575-6.

14. Mitchell ES, Jones JR, Foster AP, Millar M, Milnes A, Williams J. Clinical features of psoroptic mange in cattle in England and Wales. Vet Rec. 2012;170:359.

15. Sarre C, De Bleecker K, Deprez P, Levecke B, Charlier J, Vercruysse J, et al. Risk factors for Psoroptes ovis mange on Belgian Blue farms in northern Belgium. Vet Parasitol. 2012;190:216-21.

16. Doherty E, Burgess S, Mitchell S, Wall R. First evidence of resistance to macrocyclic lactones in Psoroptes ovis sheep scab mites in the UK. Vet Rec. 2018:182:106.

17. Sturgess-Osborne C, Burgess S, Mitchell S, Wall R. Multiple resistance to macrocyclic lactones in the sheep scab mite Psoroptes ovis. Vet Parasitol. 2019;272:79-82

18. Lifschitz A, Fiel C, Steffan P, Cantón C, Muchiut S, Dominguez P, et al. Failure of ivermectin efficacy against Psoroptes ovis infestation in cattle: integrated pharmacokinetic-pharmacodynamic evaluation of two commercial formulations. Vet Parasitol. 2018;263:18-22.

19. Brimer L, Bønløkke L, Pontoppidan C, Henriksen SA, Gyrd-Hansen N, Rasmussen F. A method for in vitro determination of the acaricidal effect of ivermectin using Sarcoptes scabiei var. suis as test organism. Vet Parasitol. 1995:59:249-55
20. Fiems L. Gewicht bij witblauwe dikbillen. Veeteelt Vlees. 2004;5:24-5.

21. Guillot FS. Population increase of Psoroptes ovis (Acari: Psoroptidae) on stanchioned cattle during summer. J Med Entomol. 1981;18:44-7.

22. Levecke B, Kaplan RM, Thamsborg SM, Torgerson PR, Vercruysse J, Dobson RJ. How to improve the standardization and the diagnostic performance of the fecal egg count reduction test? Vet Parasitol. 2018;253:71-8.

23. R Core Team (2017). R: a language and environment for statistical computing. Vienna: R Foundation for Statistical Computing. https://www.Rproject.org/.

24. Clymer BC, Janes TH, McKenzie ME. Evaluation of the therapeutic and protective efficacy of doramectin against psoroptic scabies in cattle. Vet Parasitol. 1997;72:79-89.

25. Lonneux JF, Nguyen TQ, Delhez M, Losson BJ. Antibody response after treatment in cattle infected with Psoroptes ovis. Res Vet Sci. 1997;63:57-60

26. Guillot FS, Meleney WP. The infectivity of surviving Psoroptes ovis (Hering) on cattle treated with ivermectin. Vet Parasitol. 1982;10:73-8.

27. Lonneux JF, Losson BJ. Field efficacy of injectable and pour-on moxidectin in cattle naturally infested with Psoroptes ovis (Acarina: Psoroptidae). Vet Parasitol. 1992:45:147-52.

28. Logan NB, Weatherley AJ, Phillips FE, Wilkins CP, Shanks DJ. Spectrum of activity of doramectin against cattle mites and lice. Vet Parasitol. 1993;49:67-73

29. Vercruysse J, Deprez P, Everaert D, Bassissi F, Alvinerie M. Breed differences in the pharmacokinetics of ivermectin administered subcutaneously to Holstein and Belgian Blue calves. Vet Parasitol. 2008;152:136-40.

30. Coles GC, Bauer C, Borgsteede FHM, Geerts S, Klei TR, Taylor MA. World Association for the Advancement of Veterinary Parasitology (WAAVP) methods for the detection of anthelmintic resistance in nematodes of veterinary importance. Vet Parasitol. 1992;44:35-44.

31. Vercruysse J, Rehbein S, Holdsworth PA, Letonja T, Peter RJ. World Association for the Advancement of Veterinary Parasitology (WAAVP) guidelines for evaluating the efficacy of acaricides against (mange and itch) mites on ruminants. Vet Parasitol. 2006;136:55-66.

32. Committee for medicinal products for veterinary use. In: Guideline on specific efficacy requirements for ectoparasiticides in cattle. 2005. https:// www.ema.europa.eu/en/documents/scientific-guideline/guideline-speci fic-efficacy-requirements-ectoparasiticides-cattle en.pdf. Accessed 4 Aug 2019

33. Wall R, Shearer D. Chapter 2. Mites. In: Wall R, Shearer D, editors. Veterinary ectoparasites: biology, pathology, and control. Oxford: Blackwell Science; 2001

34. Mingolla C, Hudders L, Vanwesenbeeck I, Claerebout E. Towards a biased mindset: an extended theory of planned behaviour framework to predict farmers' intention to adopt a sustainable mange control approach. Prev Vet Med. 2019;169:104695.

\section{Publisher's Note}

Springer Nature remains neutral with regard to jurisdictional claims in published maps and institutional affiliations.

Ready to submit your research? Choose BMC and benefit from

- fast, convenient online submission

- thorough peer review by experienced researchers in your field

- rapid publication on acceptance

- support for research data, including large and complex data types

- gold Open Access which fosters wider collaboration and increased citations

- maximum visibility for your research: over 100M website views per year

At BMC, research is always in progress.

Learn more biomedcentral.com/submissions 